\title{
Establishing an EU-China consortium on traditional Chinese medicine research
}

\author{
Halil Uzuner ${ }^{1 *}$, Tai-Ping Fan², Alberto Dias ${ }^{3}$, De-an Guo ${ }^{4}$, Hani S El-Nezami ${ }^{5}$, Qihe Xu
}

\begin{abstract}
Traditional Chinese medicine (TCM) is widely used in the European Union (EU) and attracts intense research interests from European scientists. As an emerging area in Europe, TCM research requires collaboration and coordination of actions. Good Practice in Traditional Chinese Medicine Research in the Post-genomic Era, also known as GP-TCM, is the first ever EU-funded $7^{\text {th }}$ Framework Programme (FP7) coordination action, aiming to inform the best practice and harmonise research on the safety and efficacy of TCM through interdisciplinary exchange of experience and expertise among clinicians and scientists. With its increasingly large pool of expertise across 19 countries including 13 EU member states, Australia, Canada, China, Norway, Thailand and the USA, the consortium provides forums and collaboration platforms on quality control, extraction technology, component analysis, toxicology, pharmacology and regulatory issues of Chinese herbal medicine (CHM), as well as on acupuncture studies, with a particular emphasis on the application of a functional genomics approach. The project officially started in May 2009 and by the time of its conclusion in April 2012 a Europe-based academic society dedicated to TCM research will be founded to carry on the mission of GP-TCM.
\end{abstract}

\section{Introduction}

Traditional Chinese medicine (TCM), especially Chinese herbal medicine (CHM) and acupuncture, is an ancient medical system used in China and other Asian countries for thousands of years $[1,2]$. In contrast to the reductionist approach of Western medicine based on modern anatomy, physiology, pathology, pharmacology as well as cell and molecular biology, TCM uses a unique system and an individualised and holistic approach to describe health and disease, based on the philosophy of Yin-Yang balance and an emphasis on harmony of functions. These two medical systems differ greatly in many respects. In the past seven years, a number of international organisations were established in mainland China, Hong Kong and Macao, including the World Federation of Chinese Medicine Societies (WFCMS, September 2003), the Consortium for Globalisation of Chinese Medicine (CGCM, December 2003) and the International Society for Chinese Medicine (ISCM, 2004).

The Good Practice in Traditional Chinese Medicine Research in the Post-genomic Era (GP-TCM) consortium was launched by the European Commission on the

\footnotetext{
* Correspondence: halil.uzuner@kcl.ac.uk

'Department of Renal Medicine, King's College London, London, UK

Full list of author information is available at the end of the article
}

$1^{\text {st }}$ May 2009. This is a three-year coordination action project funded under the EU Seventh Framework Programme (FP7) with a total budget of $€ 995,100$. The central hypothesis of the consortium is that, using functional genomics technology, which allows highcontent observations of whole profiles of molecules at different levels, eg DNA, mRNA, protein and metabolites, and furthermore linking them to clinically relevant biological functions, we might be in a better position than ever before to interpret and validate the scientific value of TCM in a holistic and function-oriented manner [3-11].

\section{Objectives}

Focusing on research of $\mathrm{CHM}$ and acupuncture, we especially emphasise studies of CHMs, their complex chemical ingredients and their holistic impact on the functional genomics of patients. The overall aim of the consortium is to inform the best practice and harmonise research on the safety and efficacy of TCM using a functional genomics approach through exchange of opinions, experience and expertise among scientists in EU member states, China and other parts of the world. Specifically, we aim to undertake the following objectives:
C Biomed Central

C 2010 Uzuner et al; licensee BioMed Central Ltd. This is an Open Access article distributed under the terms of the Creative Commons Attribution License (http://creativecommons.org/licenses/by/2.0), which permits unrestricted use, distribution, and reproduction in any medium, provided the original work is properly cited. 
- Develop a European-Chinese network, collaborating on functional genomics research of TCM;

- Review current practice of TCM research, identify problems and propose solutions;

- Propose standard protocols of methodology;

- Propose priority areas for future research;

- Develop online resources to support and enhance pan-European studies of TCM research;

- Facilitate and foster a sustainable European collaboration by founding a European society dedicated to TCM research.

\section{Structure}

As shown in Figure 1 through ten working groups known as work packages (WPs), the consortium takes actions to review the techniques, identify problems and solutions in the quality control (WP1), extraction and analysis (WP2) of CHMs. While these fundamental issues are addressed, discussion forums emphasising the use of functional genomics methodology in research of the safety, efficacy and mechanisms of CHMs (WP3WP7) and acupuncture (WP8) form the core of this coordination project. The project covers toxicology (WP3), in vitro and in vivo pharmacology (WP4-WP5), clinical studies (WP6), as well as international regulatory

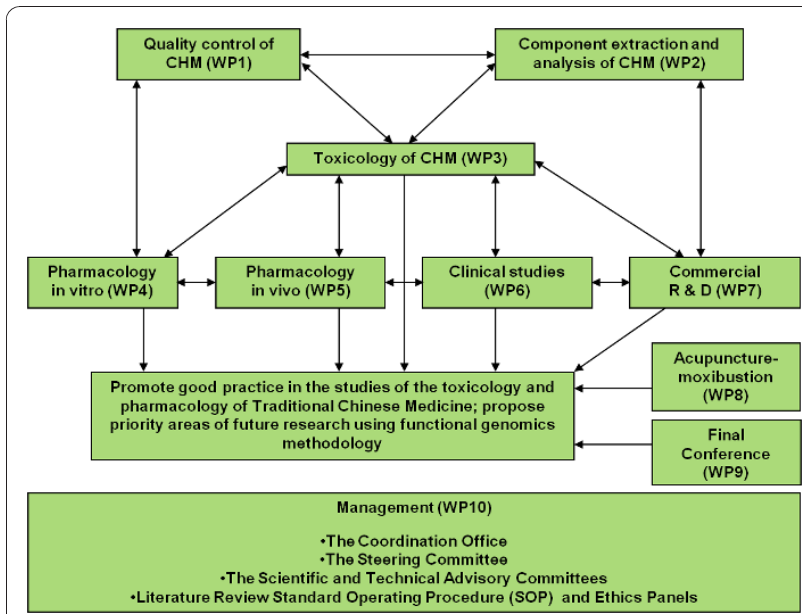

Figure 1 Structure of the GP-TCM Consortium. GP-TCM work package interaction and relationship: GP-TCM has ten interactive working groups, known as work packages (WP). WP1-WP7 specialises in quality control, component extraction and chemical analysis, toxicology, in vitro and in vivo pharmacology, clinical studies and regulatory issues in commercial R\&D respectively. WP8 is specialised in acupuncture studies and WP9 is dedicated to organising the Final conference of the consortium, at which a new European society will be launched to succeed the mission of the consortium. WP10 is the managing, coordinating and leading body of the whole consortium, aiming at integrating the expertise and collating outputs of all WPs to achieve the overall objectives of the consortium issues of CHM (WP7). WP9 is dedicated to organising the Final Conference of the consortium at the end of the project and WP10 is charged to manage consortium-wide matters, such as appointment and coordination of WP leadership, recruitment of additional experts, editing website and newsletters, drafting standard operating procedures, providing scientific and technological support and guidance, organising internal review and quality assurance, as well as liaising with the Commission and other stakeholders and external authorities.

\section{Membership}

As shown in Table 1 the consortium has 27 beneficiary (ie funded) partner organisations across ten EU member states (ie Austria, Belgium, Estonia, Germany, Ireland, Italy, the Netherlands, Portugal, Spain and the UK) and China, which is an International Cooperation Partner Country (ICPC) of the EU. The consortium has additional 60 non-beneficiary (ie unfunded) collaborating partner organisations as well as two independent experts from Australia, Austria, Belgium, China, Denmark, Finland, Germany, Italy, Luxembourg, the Netherlands, Norway, Thailand, the UK and the USA (Table 2). Please refer to the project website at http://www.gp-tcm. org/about/partners/ for an updated list of consortium partners. This forms a diverse, multicultural and multidisciplinary team of about 150 principal investigators, including leading scientists, clinicians, TCM practitioners, as well as experts in industrial development and regulatory issues. Non-beneficiary membership is mainly based on consortium invitation and requires outstanding expertise needed for the project. Interested parties are welcome to contact us via the GP-TCM website http:// www.gp-tcm.org/contact/. GP-TCM currently covers half of the $27 \mathrm{EU}$ member states and its members in China are largely in major eastern and southern cities. As an open-ended consortium, GP-TCM welcomes interested parties from all EU member states and China to join our network, sharing resources and forging collaborations. We will continue to develop and strengthen collaborations with friends in Africa, South America, Asia and non-EU European countries to exchange experience and lessons learnt in the research of traditional medicines.

\section{Progress and difficulties}

During the first 18 months of the project (May 2009-October 2010), the management team (WP10) has coordinated a highly successful team build-up and re-construction. With the ever-strengthening expertise pool, WP10 has developed a number of committees and panels that lead the consortium with clear divisions of labour. WP10 has led the design and updates of the professional GP-TCM website and all WPs have established their homepages and online 
Table 1 GP-TCM beneficiary members

\begin{tabular}{|c|c|c|}
\hline GP-TCM beneficiary partners & Country & Contact \\
\hline King's College London & UK & Dr. Qihe Xu \\
\hline University of Vienna & Austria & Prof. Verena M. Dirsch \\
\hline L’Université Libre de Bruxelles & Belgium & Prof. Pierre Duez \\
\hline Beijing University of Chinese Medicine & China & Prof Yanjiang Qiao \\
\hline China Capital Medical University & China & Prof. Xiaomin Wang \\
\hline Institute of Medicinal Plant Development & China & Prof. Xinmin Liu \\
\hline Shanghai Institute of Acupuncture-Moxibustion & China & Prof. Huangan Wu \\
\hline Shanghai University of Traditional Chinese Medicine & China & Dr. Liu Chenghai \\
\hline University of Hong Kong & China & Dr. Hani El-Nezami \\
\hline Asper Biotech Ltd & Estonia & Ms. Janne Üksti \\
\hline Federal Institute for Drugs and Medical Devices & Germany & Dr. Werner Knöss \\
\hline University of Düsseldorf & Germany & Prof. Peter Proksch \\
\hline University of Munich & Germany & Prof. Angelika Vollmar \\
\hline University of Bonn & Germany & Prof. Gabriele König \\
\hline Trinity College Dublin & Ireland & Dr. Helen Sheridan \\
\hline University of Milan & Italy & Prof. Enrica Bosisio \\
\hline University of Padova & Italy & Prof. Maria Carrara \\
\hline CMC Tasly Group BV & The Netherlands & Dr. You-Ping Zhu \\
\hline Leiden University & The Netherlands & Prof. Robert Verpoorte \\
\hline University of Minho & Portugal & Prof. Alberto Dias \\
\hline University of Alcala & Spain & Prof. F. Javier de Lucio Cazaña \\
\hline University Hospital Ramón y Cajal-FIBIO & Spain & Dr. M. Laura García Bermejo \\
\hline Acu-herb Consultant, Sheffield & UK & Ms. Dan Jiang \\
\hline University of Wolverhampton & UK & Prof. Kelvin Chan \\
\hline Royal Botanic Gardens, Kew & UK & Prof. Monique Simmonds \\
\hline University of Southampton & UK & Prof. George Lewith \\
\hline University of Cambridge & UK & Dr. Tai-Ping Fan \\
\hline
\end{tabular}

discussion facilities. Periodic newsletters have enabled members to share information and stay as a united team. Significantly, a series of face-to-face meetings, including consortium and WP kick-off meetings and the $1^{\text {st }}$ Annual General Meeting, have been organised to monitor the consortium, promote interactions and collaborations and ensure milestones are met and deliverables accomplished on time and in high quality.

Noteworthy WP-specific achievements are as follows. WP1 led the creation of a list of nearly 300 species of plants and fungi commonly used in TCM in Europe and China and a priority list of 11 species will be used by all WPs in their initial literature analysis. WP2 worked jointly with WP1, linking quality control, extraction technology and chemical analysis, with special emphasis on the important role of paozhi (processing) in the production of CHM. WP3 produced a list of toxic plants for further literature study and identified 3 major fields of action: (i) investigation of methods (classical and functional genomics) applicable to toxicity evaluation; (ii) study of toxicological reports available on a series of CHM; (iii) review of pharmacovigilance safety data.
WP4 established evaluation criteria for scoring scientific articles and began the creation of an appropriate database of literature encompassing functional genomic applications in CHM research. WP5 performed reviews on CHM literature involving animal models, especially models of cancer and its conclusions have laid a solid foundation for further literature analysis on application of functional genomics in CHM research and proposing good practice in animal studies of CHM. WP6 gathered literature on seminal studies in clinical CHM studies and drafted a guideline on clinical trials of CHM. WP6 and WP8 collaboratively designed an online survey targeting TCM practitioners and the survey is currently undergoing in collaboration with 30 professional acupuncture and TCM organisations. WP7 brought together wide-ranging experiences and expertise in drug development and registration from Europe, China, Australia and North America to discuss the legislative and regulatory issues relevant to $\mathrm{CHM}$. Together they are developing a comprehensive document providing comparisons of different practices on CHM regulations and this will be extremely helpful for the EU to develop its 
Table 2 GP-TCM non-beneficiary members

\begin{tabular}{|c|c|c|}
\hline GP-TCM Non-beneficiary partners & Country & Contact \\
\hline University of Western Sydney & Australia & Prof. Alan Bensoussan \\
\hline University of Graz & Austria & Prof. Rudolf Bauer \\
\hline University of Mons & Belgium & Prof. Jean-Marie Colet \\
\hline Beijing East Linden Science and Technology Co. Ltd. & China & Prof. Yanhuai Liu \\
\hline China Academy of Chinese Medical Sciences & China & Prof. Aiping Lu \\
\hline China-Japan Friendship Hospital & China & Prof. Ping Li \\
\hline Dalian Institute of Chemical Physics & China & Prof. Xinmiao Liang \\
\hline Hong Kong Baptist University & China & Prof. Zhongzhen Zhao \\
\hline Hong Kong Buddhist Hospital & China & Prof. Vivian Wong \\
\hline Jinan University & China & Prof. Xinsheng Yao \\
\hline Peking University & China & Prof. Wenhan Lin \\
\hline PuraPharm & China & Mr. Abraham Chan \\
\hline Shanghai Innovation Research Centre of Traditional Medicine & China & Prof. William Weiguo Jia \\
\hline Shanghai Jiaotong University & China & Prof. Liping Zhao \\
\hline Shanghai Institute of Materia Medica, Chinese Academy of Sciences & China & Prof. De-an Guo \\
\hline Tongji University & China & Prof. Gang Pei \\
\hline Tasly Institute of Tasly Group Co., Ltd. & China & Ms. Karolina J. Svedlund \\
\hline Tianjin University of Traditional Chinese Medicine & China & Prof. Boli Zhang \\
\hline University of Macau & China & Prof. Yi-Tao Wang \\
\hline The Chinese University of Hong Kong & China & Prof. Ge Lin \\
\hline Pfizer Corporation Hong Kong Ltd & China & Mr. Stephen Leung \\
\hline State Food and Drug Administration & China & Prof. Zhong-zhi Qian \\
\hline National Research Institute of Chinese Medicine, Taiwan & China & Prof. Yi-Tsau Huang \\
\hline University of Aarhus & Denmark & Prof. Brian Clark \\
\hline University of Oulu & Finland & Prof. Olavi Pelkonen \\
\hline Public Research Centre of Health & Luxembourg & Dr. Ning Wang \\
\hline Charité University Medical Center & Germany & Prof. Claudia M. Witt \\
\hline Johannes Gutenberg University & Germany & Dr. Huige Li \\
\hline University of Regensburg & Germany & Prof. Gerhard Franz \\
\hline Philipps - Universität Marburg & Germany & Prof. Shuming Li \\
\hline Max Planck Institute for Biophysics & Germany & Prof. Wolfgang Schwarz \\
\hline Dr Willmar Schwabe GmbH \& Co. KG & Germany & Dr. Günter Meng \\
\hline Caesar \& Loretz GmbH & Germany & Dr. Mirko Bayer \\
\hline University of Cagliari & Italy & Prof. Enzo Tramontano \\
\hline University of Rome Tor Vergata & Italy & Prof. Giovanna M. Franconi \\
\hline Institute of Neurobiology and Molecular Medicine, Italian National Research Council & Italy & Dr. Luigi Manni \\
\hline SU BioMedicine & The Netherlands & Prof. Jan van der Greef \\
\hline Norwegian University of Science and Technology & Norway & Prof. Odd Georg Nilsen \\
\hline Thailand Ministry of Public Health & Thailand & Dr. Prat Boonyawongviroj \\
\hline School of Pharmacy & UK & Prof. Michael Heinrich \\
\hline Brunel University & UK & Prof. Ian A. Sutherland \\
\hline University of Reading & UK & Prof. Elizabeth Williamson \\
\hline Guy's \& St Thomas' NHS Foundation Trust & UK & Prof. Debbie Shaw \\
\hline University of Nottingham & UK & Prof. Sue Watson \\
\hline University of Warwick & UK & Prof. Kenneth Muir \\
\hline University of Westminster & UK & Dr. Volker Scheid \\
\hline University of Lincoln & UK & Dr. Huijun Shen \\
\hline Thames Valley University & UK & Prof. Nicola Robinson \\
\hline University of the West England & UK & Prof. Quan Min Zhu \\
\hline Imperial College London & UK & Dr. Daqing Ma \\
\hline Global Regulatory Services & UK & Mrs. Greer Deal \\
\hline
\end{tabular}


Table 2 GP-TCM non-beneficiary members (Continued)

\begin{tabular}{|c|c|c|}
\hline Link China Pharma Solutions & UK & Mr. Marshall Ma \\
\hline University of Oxford & UK & Ms. Rebecca Richmond \\
\hline University of East London & UK & Dr. Tianjun Wang \\
\hline Avicenna & UK & Mr. Mazin Al-Khafaji \\
\hline University of Louisville & USA & Prof. Y. James Kang \\
\hline Yale University & USA & Prof. Yung-Chi Cheng \\
\hline U.S. Food and Drug Administration & USA & Dr. Shaw T. Chen \\
\hline Vanderbilt University Medical Center & USA & Dr. Lijun Ma \\
\hline Independent & UK & Dr. Shouming Zhong \\
\hline Independent & UK & Dr. Daryl Rees \\
\hline
\end{tabular}

future policies and for companies to develop products for the global market. WP9 discussed the time and format of the Final Conference and preliminary bookings of venue has been made.

The major difficulty encountered by the consortium is unsurprisingly the language barrier. There is a lack of accessibility to original Chinese publications in Europe, and even if they are available, fast and accurate translation of these materials is impossible, preventing the consortium from extensively studying classic Chinese medical literature and evaluating a great deal of modern Chinese medical literature. While we strongly encourage our members to master both English and Chinese languages, we welcome members from various linguistic, ethnic and cultural backgrounds to work in close collaboration.

\section{Further work}

As the first ever EU-China collaborative consortium dedicated to TCM research, we will continue to promote EU-China dialogues and collaborations in this important emerging supra-disciplinary area. As a network of principal investigators, we will collaborate to train the next generation of scientists who are more comprehensively equipped to study complex drugs such as $\mathrm{CHM}$ and personalised medicine such as TCM. As a coordination action involving much literature review and evaluation, we acknowledge the huge importance of good practice in scientific publication and will continue to support open-access publications.

\section{Concluding remarks}

As an EU-China collaboration dedicated to TCM research, we are keen to incorporate ourselves into the worldwide landscape of TCM research community and serve as a constructive member. We sincerely support the international TCM community to bundle forces to improve TCM research funding from both the public and private sectors and to help shape the medicine of tomorrow together.

\section{Abbreviations}

CGCM: Consortium for Globalisation of Chinese Medicine; CHM: Chinese herbal medicines; EU: European Union; FP7: Seventh Framework Programme; GP-TCM: Good Practice in Traditional Chinese Medicine Research in the Postgenomic Era; ICPC: International Cooperation Partner Country; ISCM: International Society for Chinese Medicine; TCM: Traditional Chinese medicine; WFCMS: World Federation of Chinese Medicine Societies; WPs: work packages.

\section{Acknowledgements}

This work has received funding from the European Union's Framework Programme 7 [FP7/2007-2013] under the grant agreement No 223154. The consortium thanks the European Commission for the grant, and the Chinese government, Innovation China UK and many other advisory bodies for their generous support.

\section{Author details}

${ }^{1}$ Department of Renal Medicine, King's College London, London, UK. ${ }^{2}$ Department of Pharmacology, University of Cambridge, Cambridge, UK. ${ }^{3}$ CITAB-UM, Department of Biology, University of Minho, Braga, Portugal. ${ }^{4}$ Shanghai Research Centre for TCM Modernization, Shanghai Institute of Materia Medica, Chinese Academy of Sciences, Shanghai, China. ${ }^{5}$ School of Biological Sciences, University of Hong Kong, Hong Kong, China.

\section{Authors' contributions}

The authors are the Project Manager (HU), the Coordinator (QX), Deputy Coordinators (AD, DG, TPF) and Assistant Coordinator (HE) of the GP-TCM Consortium. HU and QX jointly drafted the manuscript. All named authors took part in the revision and approved the final version of the paper.

\section{Competing interests}

The authors declare that they have no competing interests.

Received: 20 October 2010 Accepted: 14 December 2010 Published: 14 December 2010

\section{References}

1. Nestler G: Traditional Chinese medicine. Med Clin North Am 2002, 86(1):63-73.

2. Normile D: Asian medicine. The new face of traditional Chinese medicine. Science 2003, 299(5604):188-90.

3. Tilton R, Paiva AA, Guan JQ, Marathe R, Jiang Z, van Eyndhoven W, Bjoraker J, Prusoff Z, Wang H, Liu SH, Cheng YC: A comprehensive platform for quality control of botanical drugs (PhytomicsQC): A case study of Huangqin Tang (HQT) and PHY906. Chin Med 2010, 5(1):30.

4. Lam W, Bussom S, Guan F, Jiang Z, Zhang W, Gullen EA, Liu SH, Cheng YC: The four-herb Chinese medicine PHY906 reduces chemotherapyinduced gastrointestinal toxicity. Sci Transl Med 2010, 2(45):45ra59.

5. Van Wietmarschen H, Yuan K, Lu C, Gao P, Wang J, Xiao C, Yan X, Wang M, Schroën J, Lu A, Xu G, van der Greef J: Systems biology guided by Chinese medicine reveals new markers for sub-typing rheumatoid arthritis patients. J Clin Rheumatol 2009, 15(7):330-7. 
6. Lao YM, Jiang JG, Yan L: Application of metabonomic analytical techniques in the modernization and toxicology research of traditional Chinese medicine. Br J Pharmacol 2009, 157(7):1128-41.

7. Kang YJ: Herbogenomics: from traditional Chinese medicine to novel therapeutics. Exp Biol Med (Maywood) 2008, 233(9):1059-65.

8. Li SS: Commentary-the proteomics: A new tool for Chinese medicine research. Am J Chin Med 2007, 35(6):923-8.

9. Cho WC: Application of proteomics in Chinese medicine research. Am J Chin Med 2007, 35(6):911-22.

10. Gao M, Deng C, Lin S, Hu F, Tang J, Yao N, Zhang X: Recent developments and contributions from Chinese scientists in multidimensional separations for proteomics and traditional Chinese medicines. I Sep Sci 2007, 30(6):785-91.

11. Efferth T, Koch E: Complex interactions between phytochemicals. The multi-target therapeutic concept of phytotherapy. Curr Drug Targets 2010.

doi:10.1186/1749-8546-5-42

Cite this article as: Uzuner et al:. Establishing an EU-China consortium on traditional Chinese medicine research. Chinese Medicine 2010 5:42.

\section{Submit your next manuscript to BioMed Central} and take full advantage of:

- Convenient online submission

- Thorough peer review

- No space constraints or color figure charges

- Immediate publication on acceptance

- Inclusion in PubMed, CAS, Scopus and Google Scholar

- Research which is freely available for redistribution

Submit your manuscript at www.biomedcentral.com/submit 